Western University

Scholarship@Western

Aboriginal Policy Research Consortium International (APRCi)

2003

\title{
Integrating Aboriginal Peoples into Canada's Casino Industry
}

Stefan Gröschl

Follow this and additional works at: https://ir.lib.uwo.ca/aprci

Part of the Tourism Commons

Citation of this paper:

Gröschl, Stefan, "Integrating Aboriginal Peoples into Canada's Casino Industry" (2003). Aboriginal Policy Research Consortium International (APRCi). 277.

https://ir.lib.uwo.ca/aprci/277 
This article was downloaded by: [University of Western Ontario]

On: 10 December 2012, At: 08: 28

Publisher: Routledge

Informa Ltd Registered in England and Wales Registered Number: 1072954

Registered office: Mortimer House, 37-41 Mortimer Street, London W1T 3J H, UK

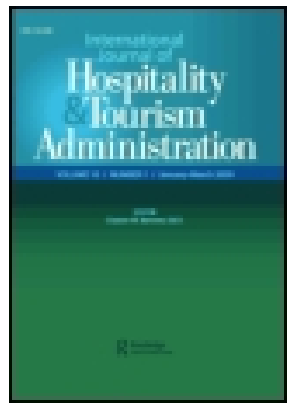

\section{International J ournal of Hospitality \& Tourism Administration}

Publication details, including instructions for authors and subscription information:

http:// www. tandfonline.com/loi/ wjht20

\section{Integrating Aboriginal Peoples into Canada's Casino Industry}

Stefan Gröschl PhD ${ }^{\text {a }}$

${ }^{a}$ School of Hospitality and Tourism Management, College of Social and Applied Human Sciences, University of Guelph, Guelph, Ontario, Canada, N1G 2W1

Version of record first published: 12 Oct 2008.

To cite this article: Stefan Gröschl PhD (2003): Integrating Aboriginal Peoples into Canada's Casino Industry, International J ournal of Hospitality \& Tourism Administration, 4:1, 87-99

To link to this article: http:// dx.doi.org/ 10.1300/J149v04n01_05

\section{PLEASE SCROLL DOWN FOR ARTICLE}

Full terms and conditions of use: http://www.tandfonline.com/page/termsand-conditions

This article may be used for research, teaching, and private study purposes. Any substantial or systematic reproduction, redistribution, reselling, loan, sub-licensing, systematic supply, or distribution in any form to anyone is expressly forbidden.

The publisher does not give any warranty express or implied or make any representation that the contents will be complete or accurate or up to date. The accuracy of any instructions, formulae, and drug doses should be independently verified with primary sources. The publisher shall not be liable for any loss, actions, claims, proceedings, demand, or costs or damages 
whatsoever or howsoever caused arising directly or indirectly in connection with or arising out of the use of this material. 


\title{
Integrating Aboriginal Peoples into Canada's Casino Industry
}

\author{
Stefan Gröschl
}

\begin{abstract}
This paper provides insights into a Canadian gaming organization and its human resources management policies and practices regarding the integration of Aboriginal peoples. The gaming organisation follows a very aggressive human resources strategy that is supported by an agreement between the provincial government and the Federation of Saskatchewan Indian Nations, and supported by unions and the $\mathrm{Hu}-$ man Rights Code of Canada. Despite its status as a gaming enterprise, Casino Regina has developed human resources tools and practices that could be adapted or applied in hospitality organisations facing similar challenges when employing Aboriginal peoples. [Article copies available for a fee from The Haworth Document Delivery Service: 1-800-HAWORTH. E-mail address: <docdelivery@haworthpress.com> Website: <http://www.HaworthPress. com> (C) 2003 by The Haworth Press, Inc. All rights reserved.]
\end{abstract}

KEYWORDS. Aboriginal peoples, human resources management, gaming industry, casinos

\section{INTRODUCTION}

Canada has long been known for being a country that welcomes and provides opportunities to immigrants from around the world. At the

Stefan Gröschl, PhD, is Assistant Professor in Human Resource Management, School of Hospitality and Tourism Management, College of Social and Applied Human Sciences, University of Guelph, Guelph, Ontario, Canada N1G 2W1 (E-mail: sgroschl@uoguelph.ca).

International Journal of Hospitality \& Tourism Administration, Vol. 4(1) 2003 http://www.haworthpress.com/store/product.asp?sku=J149

(C) 2003 by The Haworth Press, Inc. All rights reserved.

$$
\text { 10.1300/J149v04n01_05 }
$$


same time, however, Canada's relationship with its Aboriginal population ${ }^{1}$ in the past 500 years has "swung from partnership to domination, from mutual respect and co-operation to paternalism and attempted assimilation (Royal Commission on Aboriginal Peoples, 1996, Looking Forward, Looking Back, II 1). Despite many governmental and non-governmental initiatives, programs and projects, there are still many challenges Aboriginal peoples are confronted with including poverty, family breakdown, limited formal education, and unemployment.

The unemployment rate is of particular importance considering that more than one-half of Canada's 800,000 plus Aboriginal population is under the age of 25 . The next ten years will therefore witness a dramatic increase in the size of the Aboriginal working population growing three to five times as fast as its non-Aboriginal counterparts (Bergman, 2002). With unemployment rates for Aboriginal peoples being at least twice the rate of the non-Aboriginal population (Indian and Northern Affairs Canada, 2001), and the geographical distribution of Aboriginal people not coinciding with the distribution of jobs across Canada, increased pressure is placed on Aboriginal communities, the government, and the private sector to create new jobs for Aboriginal people.

Canada's hospitality industry has begun to address these issues. The gaming sector, in particular, has become an important revenue generator, and as such has developed into a significant employer in many provinces and territories for Aboriginals and non-Aboriginals (Human Resources Development Canada, 2001). The introduction of on-reserve gaming offers an important opportunity for Aboriginal communities to create jobs for their peoples and to stimulate economic development (Kelly, 2001). Thus, the gaming sector, and in particular casino organizations, provide an important source of employment for Aboriginal peoples.

So far, no published studies could be found that explore human resources (HR) related practices and processes that influence the employment and integration of Aboriginal peoples within Canadian casino organizations. The majority of studies and research institutions in the area of gambling and casinos in Canada have focused on aspects such as health and safety, problem gambling, and socio-economical factors (e.g., Keith, Cann, Brophy, Hellyer, Day, Egan, Mayville and Watterson, 2001; Posner, Leitner, and Lester, 1985; Basham and White, 2002). The Alberta Gaming Institute identified its key research areas as being bio-psychological and health care, socio-cultural, economic, and government and industry policy and practice (Alberta Gaming Research Institute, 2002). Even in the United States with its Aboriginal population facing similar challenges as their Canadian counterparts, and with its 
long history of casino operations, few studies (e.g., Anfuso, 1995) have explored general HR aspects-or those that support the employment and integration of Aboriginal peoples-in casinos within the United States.

This paper aims to provide insights into this under-researched area exploring the development and sophistication of HR related practices and processes that influence the employment and integration of Aboriginal peoples within Canadian casino organizations. For this project casinos are defined as government-recognized singular locations where gambling games are played on a regular basis and revenues are shared with public treasuries (Thompson, 2001). In this context the term casino does not include lotteries, bingo, horse racing, or video lottery terminals. Given the exploratory nature of this project a case study approach was chosen focusing on Casino Regina in Saskatchewan. As a result, this study should be seen as a snapshot only, providing the basis for comparing, contrasting, and benchmarking casinos on a provincial and national level in terms of their HR related practices and processes that influence the employment and integration of Aboriginal peoples.

The first part of this article introduces the environmental context the case study organization is operating in. This is followed by a brief outline of the history and development of Casino Regina. Thirdly, the methodological approach and tools are described. The main part discusses some of the key findings of this project. The concluding part puts forward recommendations.

\section{THE ENVIRONMENTAL CONTEXT}

Casino Regina is located in Saskatchewan, a province with the largest proportion of Indian to non-Indian population in Canada. The high fertility rates in the prairie provinces (which includes Saskatchewan) and the declining rates elsewhere will make Saskatchewan the second largest First Nations population after Ontario (Federation of Saskatchewan Indian Nations, 1997). In contrast to the aging general population, the Aboriginal population in Saskatchewan is predominantly young and is continuing to grow: "Approximately 56 percent of Saskatchewan's first nations population is under age 24, while approximately 50 percent of the Métis population is under age 24" (Saskatchewan Chamber of Commerce, 2002: 7). Thus, in the near future the Aboriginal peoples will make up a greater proportion within Saskatchewan's labour market and workforce. According to the Federation of Saskatchewan Indian 
Nations (1997) the Aboriginal proportion of the labour force will increase from 11 percent currently to 31 percent by 2045 .

The large number of remote and isolated Saskatchewan Aboriginal communities combined with the need for a highly skilled and motivated workforce due to the growth of the province's service sector to 41 percent by 2005 (Federation of Saskatchewan Indian Nations, 1997) provides challenges to the education and training of Aboriginal peoples. According to the Saskatchewan Chamber of Commerce (2002) 65 percent "of all job opportunities over the next five years will require either management skills and/or post-secondary education" (p. 8). So far, however, there is a skill shortage amongst Saskatchewan's Aboriginal potential employees and Aboriginal students' "graduation rates fall significantly behind those of non-Aboriginal students" (Saskatchewan Chamber of Commerce, 2002: 15). This could be a reflection of Saskatchewan's employment rates. The Federation of Saskatchewan Indian Nations Report (1997) shows Saskatchewan Aboriginal employment for 2005 to be 24 percent as compared to 70 percent of non-Aboriginal employment.

In summary, organizations operating in Saskatchewan have been faced with a labour pool that increasingly consists of young Aboriginal peoples with-to some extent-limited educational background and/or vocational training.

\section{HISTORICAL BACKGROUND OF GAMING IN SASKATCHEWAN}

In 1996 the White Bear Band in Saskatchewan challenged the provincial criminal code requiring Aboriginals to apply at a provincial level for permission to build and run a casino on their reserve land. The White Bear Band argued that reserve land falls under federal law and, thus, the provincial criminal code did not apply. The band opened a casino on its reserve land, which was promptly shut down. The resulting negotiations between the Saskatchewan province and the Federation of Saskatchewan Indian Nations (FSIN) provided the following key agreements:

- Two casinos would be built including one in Regina and one in Saskatoon.

- The casinos would be incorporated under the Non-Profit Corporation Act, 1995 of Saskatchewan, as a charitable corporation named Saskatchewan Gaming Corporation (SGC).

- Joint responsibility of the casinos by the province and FSIN. 
- Profit sharing between the two stakeholders.

- Aboriginal employment of at least 50 percent at every operational and managerial level.

- An experienced third party would manage the casinos.

Casino Saskatoon was never built due to objections by the majority of Saskatoon's population. In contrast, Casino Regina opened in 1996 on off-reserve land in Regina. It was operated by the Saskatchewan Gaming Corporation, a Treasury Board Crown Corporation reporting to the Saskatchewan government. In accordance with the agreement above the Saskatchewan Gaming Corporation Board of Directors was made up by three persons nominated by the Chief's Legislative Assembly of the Federation of Saskatchewan Indian Nations, and four persons recommended by the provincial cabinet. A full-service entertainment facility with 620 slot machines, 37 table games, a restaurant, and a gift shop, Casino Regina was under the management of the Dutch casino group "Holland Casinos" in Regina.

By recruiting from Aboriginal employment agencies it was hoped to attract and retain the required numbers of Aboriginal employees. However, cultural differences between the Dutch management and Aboriginal employees, the limited formal education and general pre-employment training amongst Aboriginal peoples led to employee turnover rates of more than 60 percent amongst Aboriginal employees ${ }^{2}$ (in comparison, Canada's accommodation industry in 1995 faced employee turnovers of 15 percent for full-time employees and up to 50 percent for seasonal and part-time workers (Human Resources Development Canada, 1995)). The turnaround followed in 1997 with the withdraw of Holland Casinos and its management team from Casino Regina. Before exploring the changes in terms of the new HR approach and initiatives the methodological approach and tools employed in the information gathering process of this study are outlined.

\section{METHODOLOGY}

Given the exploratory nature of this research project a case study approach was deemed the most appropriate research design. In particular its flexibility favored the case study approach over other research designs. Instead of testing hypotheses and theories, this project aimed to explore human resources management processes within their natural setting. This 
study could be seen as a "snapshot" or pilot case rather than providing data that claims external validity and statistical generalizations.

Following a triangulation approach, a number of different research tools and data collection methods were employed including reviews of company documentation, non-participant observations, semi-structured in depth interviews, and focus groups. Interviewees of Casino Regina included the President and CEO, the Vice President Human Resources and Aboriginal Affairs, the Manager of Learning and Development, and the Employee and Family Assistance Program Administrator. Other interviewees included the Director of Development of the Saskatchewan Indian Federated College, an institution strongly affiliated with the casino. One focus group discussion was conducted with Casino Regina's Aboriginal Management Development Program (AMDP) candidates; another focus group included representatives from the Saskatchewan Indian Gaming Authority (SIGA) and from the Saskatchewan Indian Federated College (SIFC). During a three-day visit nonparticipant observations were conducted in the casino's back of house (i.e., offices, training facilities) and front of house (i.e., gambling facilities, restaurants, concierge, reception). Throughout the visit documentation was collected that provided an overview of the casino's general operations, initiatives, policies, programmes, and financial situation, and HR related documents such as training and development plans, and hiring policies.

Due to the study's exploratory nature a holistic position was taken towards the overall data preparation and analysis process, focusing on the richness of the collected data rather than "turning it into numbers or ... quantitative statements" (Easterby-Smith, Thorpe, and Lowe, 1996: 105). With regard to the interviews and focus group discussions, data were organised (i.e., transcribed) as soon as it was collected. Similarly, detailed field notes and summaries of observations and informal discussions with employees were taken. Data were analyzed using a content analysis approach. The following section outlines some of the key findings regarding Casino Regina's HR approach of attracting, integrating, and retaining Aboriginal employees in its workforce.

\section{THE NEW HR APPROACH AND INITIATIVES}

With Holland Casinos having left, a new, more aggressive human resource management approach followed, starting with the hiring of Aboriginal peoples in key managerial areas and positions such as HRM. 
Lessons from the past showed the importance of developing an organizational culture and climate that would accommodate Casino Regina's Aboriginal employees' cultural value and belief system. Such an accommodating approach is justified by Redpath and O'Nielsen's (1997) comparative study of cultural values and management practices of $\mathrm{Ca}$ nadian Aboriginals and non-Aboriginals. The two researchers concluded that "Native cultures differ in fundamental ways from nonNative cultures" (p. 337). In contrast to the mainstream North American preferred value and belief systems that emphasize individual achievement, competitiveness, aggressiveness and status, Aboriginal culture focuses on collectivistic values, harmony, consensus decision making, putting family needs before business goals, and behaviour that is egalitarian (Redpath and O'Nielsen, 1997). Thus, employing Aboriginal employees in key managerial positions provided Casino Regina with the commitment and power at its organisational core necessary to transform its organisational culture towards the accommodation of its Aboriginal employees' cultural value and belief system.

One of the key changes toward that goal was the creation of the position of Director of HRM and Aboriginal Affairs, and the latter being filled with an Aboriginal individual who was familiar with local and regional Aboriginal communities. Strong links and partnerships started to be developed with a wide range of local and national recruitment sources including Aboriginal employment agencies, the Sofia House (Woman Shelter), Aboriginal Youth organizations such as the Circle Project (drop in centre for young drug abusers), Rapa-Regina Aboriginal Professional Association, Saskatchewan Visible Minority Association, Saskatchewan Independent Living Centre, and the Aboriginal Government Employee Network. Casino Regina regularly invites representatives of these agencies introducing their organizations and developing trust and strong relationships with the Casino and its employees.

The strong focus on recruiting and selecting Aboriginal people has been supported by the Casino's two unions and the Human Rights Code. Due to the agreement between the provincial government and the Federation of Saskatchewan Indian Nations mentioned earlier, the $\mathrm{Hu}-$ man Rights Code exempts Casino Regina from discriminating in favour of Aboriginal peoples.

The network of recruitment sources provides mainly low skilled, potential Aboriginal employees with limited formal education and little pre-employment training-reflecting the educational challenges mentioned earlier. As a result, Casino Regina has developed internal and external educational and training and development initiatives. Responsibility for designing and 
implementing these projects is overseen by an Aboriginal Manager for Learning and Development.

Today, Casino Regina offers internships and work placements to Aboriginal students of various educational agencies and institutions. The latter include, for example, the Saskatchewan Institute of Applied Arts, Science, and Technology, and the Cochrane High School Work Education Program. Every semester ten to fifteen students spend two to ten weeks at Casino Regina applying theoretical aspects of their office administration programs into practice providing support services in the different offices and departments of the casino.

Scholarships are awarded to Saskatchewan residents to pursue full-time post-secondary education in areas such as business administration and hospitality management. At least 50 percent of those awards are given to students of Aboriginal ancestry. Out of the fourteen scholarships awarded yearly, seven awards at $\$ 1,000$ each are designed for one-year university programs, and seven awards at \$500 support students attending a one-year college program.

Jointly with the Saskatchewan Indian Federated College (SIFC), Casino Regina developed the first ever in Canada university level courses designed specifically for the gaming and casino industry, including casino marketing, introduction to gaming administration, and casino finance and administration. All courses contain an Aboriginal component. This reflects Casino Regina's commitment to participate as an active partner in the education and training of tomorrow's Aboriginal employees in Saskatchewan.

Internal training and development programs include an Aboriginal Management Development Program (AMDP) focusing on leadership development. This initiative is for Aboriginal employees only. The AMDP enables participants to attend university to attain a post-secondary business degree or diploma of associate in business in addition to participating in an internal programme that focuses on the development of the individual and the organization. Currently seven employees participate in the AMDP. They receive two to four years paid leave depending on the length of their degree or diploma. In addition, Casino Regina pays each student's tuition fees and any additional assistance or support services such as tutoring. After completion of their studies, AMDP participants are asked to commit themselves to the company for as many years as they were on paid leave. It provides Casino Regina with a skilled and trained internal Aboriginal labour market and the opportunity for Aboriginal employees to progress toward middle and senior management positions. 
Aboriginals in management and leading positions serve as mentors and role-models to the Aboriginal members of Casino Regina's workforce and to their Aboriginal communities and increase Aboriginals' self-confidence and motivation. The lack of or limited self-confidence has been identified as a key issue by Casino Regina's senior management. According to the Aboriginal counsellor of Casino Regina's Employee and Family Assistance Program (EFAP) Aboriginal peoples often move within a vicious circle. Due to discrimination, cultural differences, differences in learning style (i.e., learning through story telling) Aboriginal students drop out of high school and college. Without a degree and/or limited literacy skills they do not find employment and, thus, could be attracted to criminal activities, drug and alcohol abuse. Casino Regina's efforts in the education, training, and provision of pre-employment experience of Aboriginal peoples, and its partnerships with Aboriginal educational and academic institutions, aims at breaking this vicious circle.

Furthermore, the Aboriginal counsellor of EFAP identified areas that were counterproductive to the accommodation of Aboriginal employees and their Aboriginal cultural heritage. Casino Regina started welcoming and harnessing native values and customs within its organisational culture. Employees could be referred to healing centres rather than conventional detoxification centres, or seek advice from an Aboriginal "Elder" rather than a regular counsellor. Casino Regina follows a case by case policy providing flexibility in areas such as giving Aboriginal employees paid/unpaid leave when attending family gatherings such as funerals, etc. This is an important aspect to Aboriginal peoples as they value their extended family and band membership. The accommodation of this collectivistic cultural value is reflected by EFAP serving not only employees' spouses and partners, but other dependents such as parents, children, brothers, sisters, fathers/mothers-in-law, grandparents, and grandchildren). Other initiatives that harness and foster Aboriginal cultural values include the recognition of Aboriginal religious and celebration dates (e.g., National Aboriginal day), and programmes such as diversity awareness training during orientation sessions of new employees, and a program for managers focusing on managing a diverse workforce. Key aspects of such programmes are cross-cultural communication and awareness.

Despite current trends towards empowering employees and managers with HR responsibilities, developing and implementing the HR programmes mentioned above require a strong and experienced HR team. Casino Regina reflects such a philosophy employing 12 profes- 
sional HR staff and four administrative/support staff. The success and effectiveness of Casino Regina's HR initiatives are monitored by diversity audits outsourced to Western University.

At the same time the diversity audits check for indications of a "brown ceiling effect." Due to the pressure of achieving the quotas outlined in the agreement between the provincial government and the Federation of Saskatchewan Indian Nations the strong focus on Aboriginal employees could lead to feelings of discrimination amongst non-Aboriginal members within Casino Regina's workforce. According to interviewees this is rarely the case for reasons such as:

- Casino Regina's HR policies are disclosed to every potential employee.

- Many other initiatives and services are open to both Aboriginal and non-Aboriginal employees (e.g., Employee and Family Assistance Program, shift-work seminars for all employees and their spouses).

- A number of initiatives focus on other minority groups within the organisation including:

- Conference of People with Disabilities in Regina, 2000.

- Yearly Saskatchewan Visible Minority Employee Association (SVMEA) Conference in Regina.

- Employee participation in monthly SVMEA committee meetings that focus on workplace barriers and workplace best practice.

- Cultural diversity programmes and awareness training workshops for all employees.

- Above average benefits such as wages for all employees.

- Every employee is either part-time or full-time employed. (Within the gaming industry this is not common practice. Instead, many employees have temporary contracts.)

So far, it seems that Casino Regina's accommodating and proactive approach toward the integration of its Aboriginal employees is going in the right direction. In 2001 a financially very profitable Casino Regina had 607 employees, of whom 52.6 percent were Aboriginal (Saskatchewan Gaming Corporation, 2001a). At a senior management level, 20 percent were Aboriginal employees, while middle managers included 33.3 percent and managers 40 percent Aboriginal peoples. Frontline positions are made up of up to 60 percent Aboriginal employees pushing the corporate average above 50 percent. The reason why the Aboriginal employment target of $50 \%$ at the different managerial levels has not been met is the fact that many Aboriginal employees leave the organisation before 
entering management positions (see labour turnover rates in next section). Due to their training and development received at an operational level these Aboriginal employees have gained the expertise and confidence to apply for jobs in fields of greater interest to them, or for places in educational institutions to continue and develop their educational training. In addition, the nature of the casino industry requires its managers to have strong technical skills that are very difficult to recruit from the outside. As a result, managers have to start "at the floor" to acquire the necessary skills and work their way up through the different ranks. Finally, as mentioned earlier, Saskatchewan's Aboriginal labour market, so far, does not provide a large number of highly skilled and educated potential Aboriginal employees suitable for other non-casino related managerial positions at Casino Regina.

Employee turnover rates in the same year was 16.5 percent, of which the turnover rate for full-time staff was 16 percent, and 19 percent for part-time staff (Saskatchewan Gaming Corporation, 2001b). Aboriginal employees (full-time and part-time) had a turnover rate of approximately 50 percent. The latter figure seems rather high. However, considering the key reasons for Aboriginal peoples to leave Casino Regina to be returning back to school and finding employment in their field of study (i.e., part-time employee who studied full-time for a teaching degree finds a teaching position) reflects Casino Regina's mission to provide the training grounds for Aboriginal peoples in Saskatchewan.

\section{CONCLUSION}

Casino Regina pursues a very aggressive and open HR approach focusing particularly on the accommodation and integration of Aboriginal employees. Experiences from the opening phase influenced Casino Regina's decision for developing an organisational culture harnessing Aboriginal cultural values and beliefs. It is this accommodating organisational culture and its proactive approach towards hiring and training and developing Aboriginal employees that could help Casino Regina to achieve the requirements outlined in the agreement between the provincial government and Federation of Saskatchewan Indian Nations.

Other casinos or gaming/hospitality organizations facing similar demographic challenges in other provinces need to be aware of Casino Regina's particular status within the Human Rights Code, and the strong involvement of members of Saskatchewan's Aboriginal community, before aiming at an equally aggressive HR approach. 
This case study has shown that employing disadvantaged groups such as Aboriginal peoples cannot be achieved by setting quotas and targets. Instead it is about developing an accommodating culture and developing a company commitment towards disadvantaged groups that goes beyond the workplace. Organisations need to shift their focus from a short-term hiring plan towards a more long-term strategy that includes potential employees' pre-employment training and their education.

This requires strong external links and partnerships with a wide range of organisations such as academic institutions and employment agencies. Despite current trends towards empowering employees and managers with HR responsibilities developing a diverse workforce requires a strong, experienced, and equally diverse HR team as seen in Casino Regina.

This case study shows that a casino does not need to be an on-reserve operation to be confronted with Aboriginal related aspects and issues described in this paper. Demographic changes similar to those faced by Casino Regina develop throughout the country, challenging other casino and gambling operations to be aware of and proactive towards the integration of their Aboriginal employees.

Due to the limited research within Canada's gaming sector focusing on HR practices, academics and practitioners might want to search for other examples from across other countries. The United States and Australia face similar issues regarding its Aboriginal population and its integration into the workforce.

\section{NOTES}

1. The Canadian Constitution recognizes three groups of Aboriginal people-Indians, Métis people (people of mixed First Nation and European ancestry), and Inuit (Aboriginal people in northern Canada, who live above the tree line in Nunavut, the Northwest Territories, Northern Quebec and Labrador).

2. There is no information available about the employee mix of full-time and part-time Aboriginal employees.

\section{REFERENCES}

Alberta Gaming Research Institute (2002). Research reveals. 1(5).

Anfuso, D. (1995). HR helps the Mirage thrive in crowded Vegas. Personnel Journal, $74(1), 72$.

Basham, P., and White, K. (2002). Gambling with our future? The costs and benefits of legalized gambling. Retrieved September 15, 2002, from http://www.frasierinstitute. ca/admin/books/files/GamblingwithOurFuture.pdf

Bergman, B. (2002). Chosen Peoples. Maclean's, January 14, 38-41. 
Easterby-Smith, M. Thorpe, R., and Lowe, A. (1996). Management research: An introduction. London: SAGE Publications.

Federation of Saskatchewan Indian Nations (1997). Saskatchewan and Aboriginal Peoples in the 21st Century: Social, Economic and Political Changes and Challenges. Regina: PrintWest Publishing Services.

Human Resources Development Canada (2001). Industry Profiles. Retrieved June 17, 2002, from http://www.hrdc-drhc.gc.ca/hrib/hrp-prh/ssd

Human Resources Development Canada (1995). Human Resources Study of the Canadian Accommodation Industry. Quebec: Human Resources Development Canada.

Indian and Northern Affairs Canada (2001). Aboriginal Labour Force Characteristics from the 1996 Census. Information Management Branch, Corporate Information Management Directorate, First Nations and Northern Statistics.

Keith, M., Cann, B., Brophy, J. Hellyer, D., Day, M., Egan, S., Mayville, K., and Watterson, A. (2001). Identifying and prioritizing gaming workers' health and safety concerns using mapping for data collection. American Journal of Industrial Medicine, 39(1), 42-51.

Kelly, R. (2001). First nations gambling policy in Canada. Canada West Foundation: Canadian Centre for Substance Abuse.

Posner, I., Leitner, L., and Lester, D. (1985). Stress in casino floor employees. Psychological Reports, 57(1), 246.

Redpath, L. and O'Nielsen, M. (1997). A comparison of native culture, non-native culture and new management ideology. Revue Canadienne des Sciences de l'Administration, 14(3), 327-339.

Royal Commission on Aboriginal Peoples (1996). People to People, Nation to Nation (Looking Forward, Looking Back, I[ 1). Retrieved June 17, 2002, from http://www.aincinac.gc.ca/ch/rcap/rpt/wrd_e.html

Saskatchewan Chamber of Commerce (2002). The Human Resources Plan- "A Call To Action." Regina: Saskatchewan Chamber of Commerce.

Saskatchewan Gaming Corporation (2001a). Annual Report 2000/2001. Regina: Saskatchewan Gaming Corporation.

Saskatchewan Gaming Corporation (2001b). Annual Representative Report 2000/ 2001. Regina: Saskatchewan Gaming Corporation.

Thomson, W. (2001). Gambling in America: An Encyclopedia of History, Issues, and Society. Santa Barbara, CA: ABC-CLIO, Inc.

RECEIVED: $10 / 29 / 02$

REVISIONS RECEIVED: 01/16/03

ACCEPTED: 01/19/03 